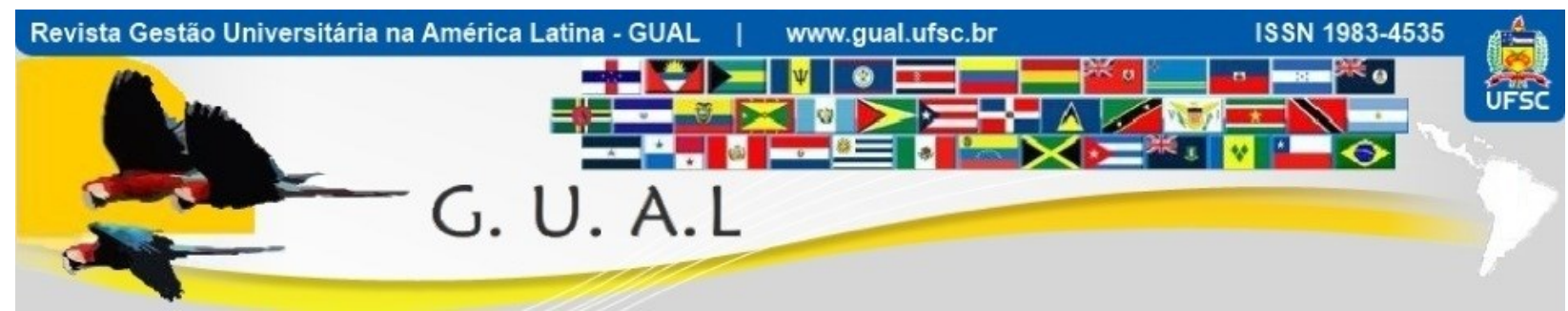

DOI: http://dx.doi.org/10.5007/1983-4535.2018v11n2p156

\title{
FATORES MOTIVADORES PARA PERMANÊNCIA DOS DISCENTES DO CURSO DE ADMINISTRAÇÃO PÚBLICA UAB/UNEMAT
}

\section{MOTIVATIONAL FACTORS FOR STAYING OF THE STUDENTS OF THE UAB I UNEMAT PUBLIC ADMINISTRATION COURSE}

Gustavo Domingos Sakr Bisinoto, Mestre Universidade do Estado de Mato Grosso - UNEMAT bisinoto@gmail.com

Marlene Valerio dos Santos Arenas, Doutora Universidade Federal de Rondônia - UNIR marlenearenas@gmail.com

Osmar Siena, Doutor Universidade Federal de Rondônia - UNIR siena@unir.br

Luciano Santos Magalhães, Mestre Universidade Federal de Rondônia - UNIR 1sm_magalhaes@hotmail.com

Eriton Holanda de Sousa, Mestre Universidade Federal de Rondônia - UNIR eriton.holanda@gmail.com

Recebido em 15/julho/2016

Aprovado em 30/janeiro/2018

Sistema de Avaliação: Double Blind Review

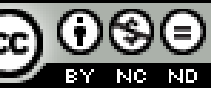

Esta obra está sob uma Licença Creative Commons Atribuição-Uso. 


\title{
RESUMO
}

A Educação a Distância $(\mathrm{EaD})$ é uma prática educativa que está consolidada no mundo. A Universidade do Estado de Mato Grosso (UNEMAT) faz parte do Programa Nacional de Formação em Administração Pública (PNAP) e oferta o curso de Bacharelado em Administração Pública através da Diretoria de Educação a Distância. O processo de formação na modalidade $\mathrm{EaD}$ é influenciado por uma série de fatores que devem ser considerados. A pesquisa quali-quantitativa buscou descobrir quais fatores mais influenciam os alunos a permanecerem no curso, através da análise do perfil do aluno e dimensões que envolvem o contexto deste aluno frequente no final do curso. Como resultado, obteve-se um perfil de aluno amadurecido, pertencente à baixa e média classe média, responsável, que se relaciona bem com a família, colegas de sala e tutores presenciais; que encontraram diversas dificuldades relacionadas aos contextos geográficos, logísticos e tecnológicos, mas souberam superá-las, mediante apoio da família e motivação para uma vida melhor (profissionalmente e financeiramente) após a conclusão do curso. Como sugestão de melhoria, propõe-se a adoção de métodos de ensino que atenda as especificidades, maior interação com os professores, uso de diversos mecanismos de comunicação, ação política da UNEMAT para cobrar melhorias nos acessos aos polos e a implantação da Avaliação Institucional no final de cada semestre letivo.

Palavras-chave: Gestão da Permanência. EaD. UAB. UNEMAT

\begin{abstract}
The Distance Education course, is an educative practice, which is consolidated in the world. The UNEMAT, part of the program PNAP, offers the Public Administration, a bachelor course, through Distance Board Education. The formation process in the Distance Education course is influenced by a whole series of factors that must be considered. This qualitative and quantitative research aimed to find out which factors are more influence to do the learners remain on course. As a result, we obtained a responsible and mature student profile belonging to low class and middle class, who relates well with the family, classmates and present tutors; that found several difficulties related to the geographical contexts, logistical and technological, but they overcame them, thought support of the family and motivation for a better life (professional and financial life) after conclusion of the course. As suggestion of improvement, we propose the adoption of teaching methods that solve the specificities, greater interaction with the teachers, the use of various communication mechanisms, UNEMAT's political action for collect improvements in access to the poles and the implementation of the Institutional Evaluation at the end of each semester.
\end{abstract}

Keywords: Management of permanence. Distance education course. UAB. UNEMAT; 


\section{FATORES MOTIVADORES PARA PERMANÊNCIA DOS DISCENTES DO CURSO DE

\section{INTRODUÇÃO}

Até poucos anos, os cursos de Administração, assim como os demais cursos superiores do país, eram ofertados apenas presencialmente. Porém, com o acentuado desenvolvimento da tecnologia da informação e o advento da internet, vários cursos de graduação e pósgraduação, dentre esses os da área de Administração, passaram a ser oferecidos também na modalidade à distância.

Outro fator que revolucionou a área de aprendizagem foi a democratização do ensino. As oportunidades de acesso ao ensino superior têm trazido à tona questões novas, haja vista a heterogeneidade de alunos no que concernem as diferenças no desempenho, condições socioeconômicas, background cultural, entre outros fatores intervenientes na relação ensinoaprendizado. Essas diferenças se acentuam ao considerarmos o ensino à distância. Isto porque não somente lidar com a diversidade é um desafio para a instituição de ensino, mas, sobretudo a manutenção dos vínculos entre instituição e discentes. Tomando como base os desafios advindos da interculturalidade na educação à distância, este trabalho ingressa na pesquisa sobre os fatores que influenciam na permanência do aluno virtual no ensino superior.

Para ampliar a compreensão sobre os fatores influenciadores do processo de evasão na formação de administradores públicos no contexto da educação à distância, surgiu o interesse em desenvolver um estudo que respondesse a seguinte questão: quais os fatores que motivam as pessoas a permanecerem no curso de Bacharelado em Administração Pública? Para a realização da pesquisa buscou-se como objetivo geral descobrir quais os fatores que motivam as pessoas a permanecerem no curso de bacharelado em administração pública. Algumas questões desdobraram-se como objetivos específicos para estudo: descrever qual é o perfil socioeconômico dos alunos do curso de bacharelado em administração pública da UAB/UNEMAT; analisar se esse perfil tem influencia na permanência ou evasão; examinar os fatores que motivaram-lhes a escolher e ingressar no curso; compreender dentro das cinco dimensões, quais os fatores mais significativos para permanência ou evasão do aluno.

Este estudo mostra-se relevante devido à sua contribuição prática e social. A identificação do perfil socioeconômico do aluno virtual de bacharelado em administração pública, assim como das relações existentes entre as diferenças individuais e do estado de motivação dos alunos inseridos nesse contexto permitirá a visualização e compreensão da interferência de fatores mediadores da aprendizagem em ambiente virtual, podendo assim 


\section{FATORES MOTIVADORES PARA PERMANÊNCIA DOS DISCENTES DO CURSO DE

contribuir para o desenvolvimento e aperfeiçoamento dos cursos nesse formato, bem como gerar melhorias no ensino e na formação do administrador público.

\section{FUNDAMENTAÇÃO TEÓRICA}

A Educação a Distância (EaD) é uma prática que já está consolidada no mundo ocidental há muitos anos. No Brasil, por muito tempo acreditou-se que não era possível fazer ensino regular à distância, o que ocasionou um represamento da $\mathrm{EaD}$ no país. Todavia, ainda que a EaD não seja a modalidade predominante no ensino brasileiro, ela já se faz presente no processo educacional, tanto em instituições públicas quanto privadas (SARTORI, 2002, p. $38)$.

Laruccia, Almeida e Ruiz (2010) destacam que a educação a distância tem ocupado um lugar expressivo na sociedade do conhecimento. O número de cursos a distância em nível de graduação e pós-graduação universitária vêm crescendo no Brasil, onde as matrículas de graduação EaD (incluindo cursos de licenciatura, bacharelado e tecnológicos) correspondem a $15,83 \%$ do total de cursos de nível superior oferecidos (MEC/INEP, 2012) ${ }^{1}$.

Convém destacar, que o processo de formação na modalidade à distância é influenciado por uma série de fatores, tais como: perfil e características intrínsecas ao aluno, metodologia utilizada no curso, a estrutura e a organização do ambiente virtual e relação do aluno com os demais agentes envolvidos no processo de aprendizagem. Nesse cenário, compreender o sistema de ensino-aprendizagem e conhecer o perfil do aluno inserido nesta modalidade de ensino são aspectos fundamentais para o avanço da Educação à Distância.

Os alunos que estudam na modalidade à distância têm diversas formações e necessidades, origens em variados grupos socioeconômicos, diferentes idades e compromissos familiares. Conhecer o perfil e o estilo de aprendizagem, incluindo anseios, motivações e limitações, do aluno que opta por esta modalidade, abre possibilidades de se adequar o planejamento e a didática do ensino às necessidades dos envolvidos.

$\mathrm{Na}$ Educação a Distância, as fontes de incentivo devem ser uma constante, onde pressupõe-se o uso da mídia e estando os alunos e professores distantes uns dos outros. As interações são possíveis, não somente porque elas permitem o acesso ao aluno para receber a

\footnotetext{
${ }^{1} \mathrm{MEC} / \mathrm{INEP}$. Censo da educação superior 2012: resumo técnico. Brasília, 2014. Disponível em: $<$ http://download.inep.gov.br/download/superior/censo/2012/resumo_tecnico_censo_educacao_superi or_2012.pdf $>$. Acesso em: 6/ jul. 2015.
} 


\section{FATORES MOTIVADORES PARA PERMANÊNCIA DOS DISCENTES DO CURSO DE

informação, mas também porque proporcionam a participação nas demais interações. (BOLZAN, 1998, p.26).

Vygotsky (1993) destaca que o aprendizado depende da interação dos indivíduos envolvidos no processo, ou seja, a aprendizagem envolve a interação social. Para o autor, o ser humano cresce em um ambiente social e o seu desenvolvimento está associado à interação com outras pessoas. Dewey $(1973$, p. 23) corrobora, afirmando que "[...] toda educação é social, sendo, como é, uma participação, uma conquista de um modo de agir comum.”.

Devido a pressões internas como o desejo de aumentar a satisfação no trabalho, de maximizar a autoestima e melhorar a qualidade de vida, o aprendiz adulto apresenta-se mais motivado para aprender. Embora não se desconsidere as motivações externas como uma melhor opção de emprego, aumento salarial, promoção de cargo, entre outros, evidencia-se que, no adulto, as motivações internas são as mais significativas. Wlodowski (1985, apud KNOWLES; HORTON; SWANSON, 2011, p. 199), definem que:

“[...] o que move um aprendiz adulto a se motivar para aprender é a soma de quatro fatores: (1) ter sucesso na aprendizagem; (2) ter a sensação de que está aprendendo aquilo que ele mesmo escolheu aprender; (3) buscar aprender algo que ele valoriza; e (4) a aprendizagem é vista como uma experiência de prazer.".

A teoria da expectativa de Vroom (1995, apud KNOWLES; HORTON; SWANSON, 2011, p. 200), tratada como a teoria clássica da motivação de adultos no ambiente de trabalho, baseia-se em três fatores “[...] (1) o valor colocado no resultado; (2) a probabilidade de que os resultados serão alcançados, dado que certos resultados aconteçam; e (3) a crença que uma pessoa tem de que um determinado esforço levará a resultados que serão recompensadores.”.

De acordo com Cislaghi (2008), a permanência é a situação na qual o estudante mantém interesse, a motivação e encontra na IES as condições que considera essenciais para permanecer frequentando regularmente o curso de graduação no qual ingressou.

Verifica-se que as questões de ordem acadêmica, as expectativas do aluno em relação à sua formação e a própria integração do estudante com a instituição constituem, na maioria das vezes, os principais fatores que podem desestimular o investimento (de tempo ou financeiro) do aluno para conclusão do curso. Ou seja, ele acredita que o custo benefício do "sacrifício" para obter um diploma superior na carreira escolhida não vale mais a pena.

Com a perspectiva de ampliar o número de egressos no ensino superior, o governo tem desenvolvido diversas iniciativas, dentre essas elenca-se o Programa Nacional de Formação 


\section{FATORES MOTIVADORES PARA PERMANÊNCIA DOS DISCENTES DO CURSO DE

em Administração Pública (PNAP), que objetiva ofertar cursos gratuitos na área de Administração, em níveis de graduação e pós-graduação por meio do ensino à distância (CAPES, 2011).

Todavia, um dos problemas enfrentados no cumprimento dessa meta é a evasão que, diga-se, é um problema generalizado. As perdas de alunos que iniciam, mas não terminam seus cursos, têm reflexos sociais, acadêmicos e econômicos. O problema é maior quando se considera a ociosidade de professores, funcionários, equipamentos e estrutura física. São comuns relatos de gestores educacionais de que os motivos da evasão estão centrados em problemas financeiros e acadêmicos.

Estudos já divulgados de evasão (PEIXOTO; BRAGA, 1998; SILVA FILHO, et al., 2007) indicam que acadêmicos evadem por dificuldades relacionadas a relacionamentos, geografia, logística e comportamento. Estas dificuldades são tão ou mais maléficas para a permanência do acadêmico na instituição quanto as financeiras e acadêmicas.

Em termos de contribuição científica, observa-se que embora a modalidade de educação a distância tenha evidenciado ano a ano seu intenso crescimento, e que a mesma já venha sendo tratada enquanto tema de pesquisa científica, são poucos os estudos que abordam políticas de gestão da permanência dessa modalidade de ensino alinhadas à abordagem possivelmente andragógica; que dê atenção aos objetivos e propósitos para o aprendizado e as particularidades contextuais, incluindo as diferenças individuais e situacionais, mantendo a motivação e o foco na qualidade do aprendizado. Por gestão da permanência entende-se o trabalho centrado no relacionamento e em condições que permitam que o acadêmico sinta e faça parte do processo educacional como um todo.

\section{METODOLOGIA}

A metodologia empregada na pesquisa é de natureza quali-quantitativa, uma vez que utiliza dos instrumentos teóricos e análise de dados descritivos em conjunto com o levantamento estatístico e estudo de frequência dos índices de evasão dos discentes da Instituição Estadual (IE) investigada.

A pesquisa tem postura multidisciplinar, utilizando diferentes abordagens teóricocientíficas. A pesquisa está inserida no contexto dos fenômenos sociais e este é constituído de inter-relações complexas, e por isso exige do investigador diferentes estratégias que possam contribuir para a compreensão das implicações com a realidade e com os grupos sociais. 


\section{FATORES MOTIVADORES PARA PERMANÊNCIA DOS DISCENTES DO CURSO DE

Utilizou-se como objeto de pesquisa os discentes matriculados nas turmas 2012/1 e 2012/2 no curso de Bacharelado em Administração Pública oferecido pela Universidade Estadual do Mato Grosso (UNEMAT). A população compreende o total de 832 alunos que estão matriculados no sistema acadêmico no semestre letivo de 2015/1 e ativos no ambiente virtual de aprendizagem (AVA). A amostra não probabilística foi de 183 alunos, sendo o mínimo de oito participantes por polo (com o mínimo quatro de cada gênero). A pesquisa foi desenvolvida em três etapas.

A primeira etapa consistiu na revisão da literatura, a fim de levantar as produções acadêmicas que têm sido desenvolvidas. Movido pela busca do conhecimento já construído relacionados ao tema deste estudo, foi realizado um levantamento bibliográfico junto ao Banco de Teses e Dissertações da Coordenação de Aperfeiçoamento de Pessoal de Nível Superior (CAPES) através da utilização das palavras-chave: "Gestão da Permanência no Ensino Superior", "Permanência no Ensino Superior", "Permanência em EaD", "Fatores de Motivação no EaD”. A segunda etapa consistiu na aplicação dos questionários, mesclando questões abertas e fechadas para identificação dos fatores motivadores da permanência elaborado em conformidade com os objetivos propostos. Os dados serviram para identificar as percepções dos alunos quanto ao contexto pessoal, institucional, geográfico, logístico e tecnológico dos quais estão inseridos. A terceira etapa consiste na proposição de intervenção/melhoria para a gestão da Universidade do Estado de Mato Grosso. A análise das respostas abertas foi realizada por meio de um processo de categorização e de uma operação de classificação dos elementos constitutivos do conjunto de dados segundo os procedimentos de análise de conteúdo de Bardin (2011).

\section{RESULTADOS E ANÁLISE DOS DADOS}

A UNEMAT faz parte do PNAP desde 2010, ofertando o curso de graduação em administração pública e as pós-graduações em gestão pública, gestão municipal e gestão em saúde. No curso de administração pública da UAB/UNEMAT o número de alunos evadidos é significativo, representando um valor aproximado de $20 \%$ a $46 \%$, dependendo do polo e turma. A evasão, contraponto da permanência, ocorre mais acentuadamente nos três semestres iniciais do curso e depois se estabiliza.

O curso de bacharelado em administração pública é ofertado em 48 instituições de ensino superior por todo país. Tem como objetivo geral formar profissionais com amplo 


\section{FATORES MOTIVADORES PARA PERMANÊNCIA DOS DISCENTES DO CURSO DE

conhecimento de administração pública, capazes de atuarem no âmbito federal, estadual e municipal, administrando com competência as organizações governamentais e nãogovernamentais. O público-alvo do curso de administração pública são portadores de diploma do ensino médio que residem nas regiões dos municípios polos de apoio presencial do curso de administração pública da UAB, que exerçam ou não função ou cargo público. Os alunos são selecionados por processo seletivo tipo vestibular, organizado pela UNEMAT. Atualmente o curso é ofertado em 11 polos de apoio presencial em Mato Grosso, conforme discriminado na tabela 1.

Tabela 1 Ingressantes no curso de Bacharelado em Administração Pública - Vagas ofertadas/preenchidas no vestibular por semestre letivo de ingresso.

\begin{tabular}{cccccc}
\hline Polos & $\begin{array}{c}1^{\text {a }} \text { Turma } \\
2010 / 2\end{array}$ & $\begin{array}{c}2^{\text {a }} \text { Turma } \\
2012 / 1\end{array}$ & $\begin{array}{c}3^{\text {a }} \text { Turma } \\
2012 / 2\end{array}$ & $\begin{array}{c}4^{\text {a }} \text { Turma } \\
2014 / 1\end{array}$ & $\begin{array}{c}5^{\text {a }} \text { Turma } \\
2014 / 2\end{array}$ \\
\hline Alto Araguaia & $75 / 75$ & $100 / 100$ & $100 / 100$ & & $50 / 50$ \\
Arenápolis & & & & $50 / 50$ & \\
Campo Verde & & & $50 / 50$ & \\
Colíder & & & & $50 / 50$ & $50 / 50$ \\
Comodoro & & $100 / 100$ & $100 / 100$ & & \\
Guarantã do Norte & $75 / 75$ & $100 / 100$ & $100 / 100$ & & $50 / 50$ \\
Jauru & $75 / 75$ & $100 / 100$ & $100 / 100$ & & $50 / 50$ \\
Juara & $75 / 75$ & & $50 / 50$ & & $50 / 50$ \\
Juína & & $100 / 100$ & $100 / 100$ & & $50 / 50$ \\
Pontes e Lacerda & $75 / 75$ & & & & $50 / 50$ \\
Sapezal & & & &
\end{tabular}

Fonte: Elaborado pelo autor com base no SISUAB/CAPES. Dados acessados em 15/09/2014.

O curso em estudo possui 1.650 alunos matriculados e aproximadamente 1.248 alunos frequentes. Nota-se dentre os matriculados, uma evasão aproximada de 402 alunos, o que corresponde a $24,36 \%$ (dados dos autores com base nas desistências dos alunos registradas no SISUAB). Esse valor é relativamente alto, se comparado com os dados do CensoEaD.BR ${ }^{2}$, onde consta uma evasão média em diferentes cursos $\mathrm{EaD}$ de 11,74\%.

Em média, cada polo atende cerca de 10 cidades circunvizinhas. Conforme dados coletados no Sistema Acadêmico do curso, aproximadamente 54,39\% dos alunos que fizeram a matrícula inicial são da cidade polo; $38,25 \%$ são de cidades circunvizinhas ao polo e estão no estado de Mato Grosso e 7,37\% residem em cidades próximas ao polo, mas fora do Estado de Mato Grosso. O estudo se concentrará nas turmas ingressantes em 2012/1 e 2012/2. A fim

\footnotetext{
${ }^{2}$ CENSO EAD.BR. Relatório analítico da aprendizagem a distância no Brasil 2012Curitiba: Ibpex, 2013.
} 


\section{FATORES MOTIVADORES PARA PERMANÊNCIA DOS DISCENTES DO CURSO DE

de contextualizar o ambiente em estudo, demonstra-se na tabela 2 um panorama dos polos estudados.

Nota-se que os polos situam-se em pequenas cidades com um IDH médio-alto e com pelo menos uma IES além da UNEMAT. Apesar de serem cidades pequenas e ruralizadas, possuem uma infraestrutura suficiente para comportar a demanda por ensino superior. Todas estas cidades possuem alguma vinculação com a atividade rural/agrícola/agropecuária, seja por produção, armazenamento ou escoamento. O fato de constarem outras IES na cidade polo, poderia influenciar algumas desistências, pois ofertam cursos mais voltados para a formação geral em administração ou mesmo na área agrícola/agropecuária.

Tabela 2 Panorama dos Polos de Apoio Presencial ofertantes do curso de Bacharelado em Administração Pública da UAB/UNEMAT.

\begin{tabular}{lccccc}
\hline \multicolumn{1}{c}{ Polos } & $\begin{array}{c}\text { População } \\
\text { Estimada } \\
2014\end{array}$ & IDH - M & $\begin{array}{c}\text { Quantidade de } \\
\text { IES } \\
\text { Pública/Particular }\end{array}$ & $\begin{array}{l}\text { Istalações } \\
\text { Físicas / } \\
\text { Polo }\end{array}$ & $\begin{array}{c}\text { Instalações } \\
\text { Tecnológicas } \\
\text { / Polo }\end{array}$ \\
\hline Alto Araguaia & 17.168 & 0,704 alto & $2 / 3$ & Ótimo & Ruim \\
Colíder & 31.707 & 0,713 alto & $2 / 5$ & Ótimo & Ruim \\
Guarantã do Norte & 33.632 & 0,703 alto & $2 / 2$ & Bom & Ruim \\
Jauru & 9.482 & 0,673 médio & $2 / 0$ & Ótimo & Regular \\
Juara & 33.483 & 0,682 médio & $4 / 3$ & Bom & Regular \\
Juína & 39.640 & 0,716 alto & $3 / 7$ & Ruim & Péssimo \\
Pontes e Lacerda & 42.924 & 0,703 médio & $3 / 2$ & Regular & Regular \\
\hline
\end{tabular}

Fonte: Elaborado pelos autores com base no SISUAB/CAPES ${ }^{3}$.

O questionário foi disponibilizado eletronicamente por meio do AVA entre os dias 11 a 23/06/2015. Os polos disponibilizaram computadores com acesso à internet e os tutores presenciais auxiliaram na aplicação, em especial no dia 14/06/2015, quando houve atividades presenciais nos polos. Dos 832 alunos matriculados ativos das turmas 2012/1 e 2012/2, 183 participaram da pesquisa.

\subsection{PERFIL SOCIOECONÔMICO}

O gráfico 1 apresenta a distribuição dos 183 participantes da pesquisa. Convém ressaltar a baixa adesão relativa do polo de Alto Araguaia pela ausência dos tutores presenciais para aplicação. Os polos de Colíder e Juína possuem apenas uma turma (2012/2)

\footnotetext{
${ }^{3}$ Dados acessados em 15/09/2014. Instituto Brasileiro de Geografia e Estatística - IBGE 2014 - População estimada para 01/07/2014. Programa das Nações Unidas para o Desenvolvimento - Índice de Desenvolvimento Humano para os Municípios IDH-M em 2013. Sistema eletrônico de acompanhamento dos processos que regulam a educação superior no Brasil (e-MEC) em 2015. Instalações Físicas e Tecnológicas dos polos: observação dos autores. Escala: Ótimo; Bom; Regular; Ruim; Péssimo.
} 
contemplada neste estudo e por isso apresentam uma participação menor em relação aos outros polos. Outro dado importante a se destacar é quanto ao gênero. Na época da matrícula inicial constavam uma média de 55\% alunas e $45 \%$ alunos. Na pesquisa obteve-se o resultado de 69,90\% participantes do gênero feminino e 30,10\% do gênero masculino. Quanto à faixa etária dos participantes, nenhum dos participantes está na faixa de 15 a 19 anos e apenas $13,10 \%$ estão com até $24 \operatorname{anos}^{4}$. Outra constatação revela que 59,10\% dos participantes estão na faixa etária compreendida entre 25 a 39 anos. Tal informação destaca um perfil de aluno do tipo adulto, em teoria, mais responsável e amadurecido.

Gráfico 1 Distribuição dos participantes da pesquisa por polo.

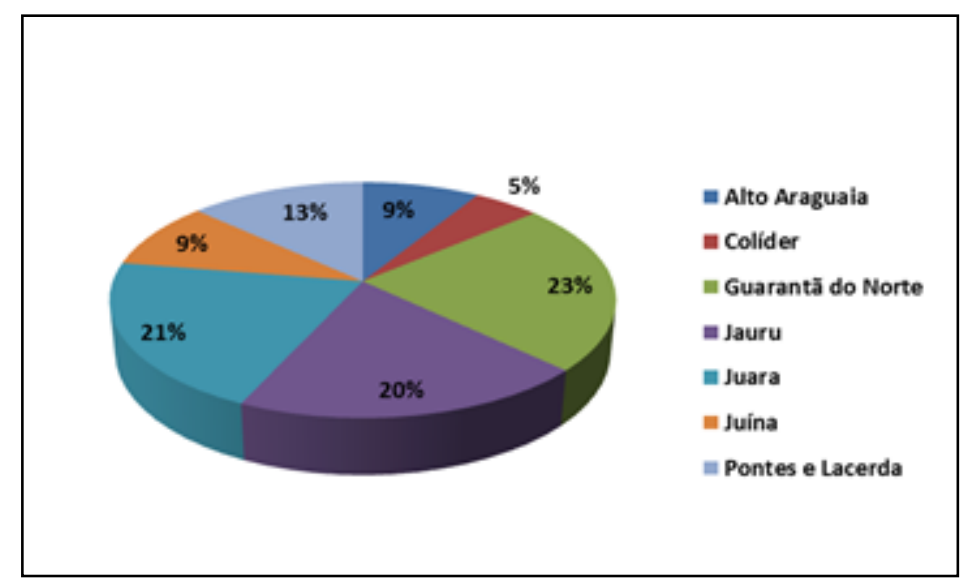

Fonte: Dados coletados pelos autores mediante questionário eletrônico.

Quanto à renda familiar média aproximada dos alunos, conforme gráfico 2, que $57,92 \%$ dos alunos possuem renda familiar compreendida no intervalo de R\$1.484,01 a R\$ 4.681,00 (equivalente a aproximadamente 1,88 a 5,94 salários mínimos em vigência) ${ }^{5}$. De acordo com a Associação Brasileira de Empresas e Pesquisas (ABEP, 2014) ${ }^{6}$, estes alunos pertenceriam à "baixa classe média" e "média classe média", fator este significante na busca da melhoria da renda familiar através da qualificação profissional.

\footnotetext{
${ }^{4}$ O IBGE (1999) reconhece o público jovem na escala de 14 a 24 anos.

${ }^{5}$ Salário mínimo vigente em Abril de 2015, no valor de R \$ 788,00.

${ }^{6}$ Classificação disponível em: http://www.abep.org/Servicos/Download.aspx?id=01 .
} 


\section{FATORES MOTIVADORES PARA PERMANÊNCIA DOS DISCENTES DO CURSO DE

Gráfico 2 Renda familiar média aproximada dos alunos.

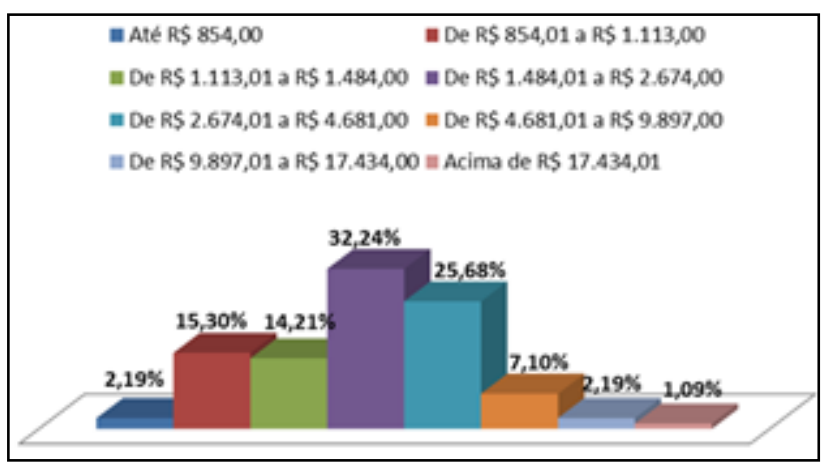

Fonte: Dados coletados pelos autores mediante questionário eletrônico.

\subsection{DIMENSÃO DE RELACIONAMENTOS}

O ser humano somente se torna uma pessoa inteiramente viva quando se relaciona com outros, pois tanto uma pessoa isolada, quanto a célula de um organismo vivo, não sobrevive. Para Aristóteles (1997), o homem é um animal social. Com a pesquisa, notou-se um apoio significativo dos agentes envolvidos no processo de ensino-aprendizagem, bem como da família. Na tabela 3 consta uma síntese do resultado.

Constata-se que o relacionamento entre os colegas e os tutores presenciais é representado como "ótimo" ou "bom" por mais de 90\% dos alunos. São pessoas que se relacionam cotidianamente ou pelo menos uma vez por mês nos encontros presenciais. Quanto aos tutores à distância e professores, a avaliação se enquadrou como "bom" ou "regular" por aproximadamente $75 \%$ dos entrevistados, sendo que os primeiros apresentaram também aproximadamente $7 \%$ de rejeição. Por fim, a coordenação de curso também teve sua avaliação como "bom" e um equilíbrio entre "ótimo" e "regular".

Tabela 3 Avaliação dos alunos quanto à dimensão relacionamento com os atores envolvidos no processo de Educação a Distância.

\begin{tabular}{ccccccc}
\hline $\begin{array}{c}\text { Avaliação } \\
\text { Atores }\end{array}$ & Ótimo & Bom & Regular & Ruim & Péssimo & $\begin{array}{c}\text { Não me } \\
\text { relaciono }\end{array}$ \\
\hline Colegas de Sala & $33,34 \%$ & $54,64 \%$ & $9,29 \%$ & --- & --- & $2,73 \%$ \\
Tutores Presenciais & $44,81 \%$ & $48,09 \%$ & $5,46 \%$ & --- & --- & $1,64 \%$ \\
Tutores a Distância & $10,93 \%$ & $45,90 \%$ & $29,51 \%$ & $6,01 \%$ & $1,09 \%$ & $6,56 \%$ \\
$\quad$ Professores & $13,66 \%$ & $52,46 \%$ & $23,50 \%$ & $1,64 \%$ & --- & $8,74 \%$ \\
Coordenação de & $21,31 \%$ & $51,36 \%$ & $19,13 \%$ & $1,64 \%$ & $0,55 \%$ & $6,01 \%$ \\
$\quad$ Curso & & & & &
\end{tabular}

Fonte: Dados coletados pelos autores mediante questionário eletrônico. 


\section{FATORES MOTIVADORES PARA PERMANÊNCIA DOS DISCENTES DO CURSO DE

Outro ponto abordado na pesquisa foi quanto a participação da família como apoio para permanência no curso. Em geral, apenas seis alunos relataram não contar com o apoio da família, em especial por exigir demais a presença do aluno, fazendo-o escolher entre dedicar o tempo aos estudos ou a ela. Outros quatro alunos relataram ser indiferente o apoio dado pela família como motivação para os estudos. O restante mencionou total apoio da família para continuidade dos estudos. Além do apoio moral e psicológico, alguns alunos relataram que recebem ajuda financeira para continuar os estudos. Os familiares projetam esperanças de que este sacrifício trará melhorias no futuro não só no aspecto individual do aluno, mas também para sua família.

Vale ressaltar que, como visto na tabela 2 , as cidades são, relativamente, pequenas. A associação de número de vagas ofertadas e cidades pequenas faz com que o curso contenha uma gama de pessoas da mesma família. Nas turmas é comum observar a participação de casais, pais e filhos, primos e tios entre outros graus de parentesco. Essa familiaridade, auxilia no compartilhamento de saberes e experiências.

\subsection{DIMENSÃO GEOGRÁFICA}

A dimensão geográfica, contempla os aspectos relativos ao local onde o aluno reside, estuda, bem como a distância aproximada de deslocamento. Notou-se que 54,6\% dos alunos não residem na cidade polo e necessitam se deslocar de três a seis vezes por semestre para participar dos encontros presenciais. Quanto ao local onde residem, 87,4\% afirmaram morar em área urbana e destes, $44,8 \%$ chegam a percorrer até nove quilômetros para ir até o polo participar das atividades.

Em seguida, 161 alunos relataram ter alguma dificuldade de acesso ao polo. Dentre as mais citadas, podemos destacar (em ordem decrescente de apontamento): 1 - Distância de onde reside até onde estuda; 2 - Péssimas condições das estradas e vias de acesso (buracos, atoleiros ausência ou quebra de pontes); 3 - Indisponibilidade ou ausência de transporte coletivo; 4 - Indisponibilidade ou ausência de carona; 5 - Falta de condições para permanência do aluno no polo ou na cidade polo. 


\subsection{DIMENSÃO LOGÍSTICA}

A dimensão logística aprofunda a dimensão geográfica, buscando compreender os meios que os alunos utilizam para estudar e frequentar o polo. Em geral, os municípios não oferecem transporte coletivo. Convém destacar que em alguns casos não oferecem nem mesmo para atender a zona rural. Apenas um polo (Juína) fica bem afastado do centro da cidade. Os outros seis polos localizam-se no centro ou próximo a ele. Ressalta-se que as situações das ruas e avenidas das cidades estão em estado intermediário-bom de conservação. Porém a situação das estradas (pavimentadas ou não) e pontes é bem precária, em especial por serem em grande parte de competência estadual e por estarem sem manutenção adequada a mais de três anos (fato este ocasionado pela priorização das obras da copa em 2014). As rodovias federais estão em estado bom ou ótimo de conservação, porém apresentam um grande fluxo de veículos que escoam a produção agrícola.

O gráfico 3 ilustra o meio de transporte utilizado pelos alunos para ir ao polo. O mais utilizado é o carro próprio (ou da família), correspondendo a aproximadamente 32\%, seguido de motocicleta/motoneta (aproximadamente 28\%). A carona de carro ou motocicleta/motoneta representa aproximadamente $19 \%$.

Gráfico 3 Meios de locomoção dos alunos para irem até o polo.

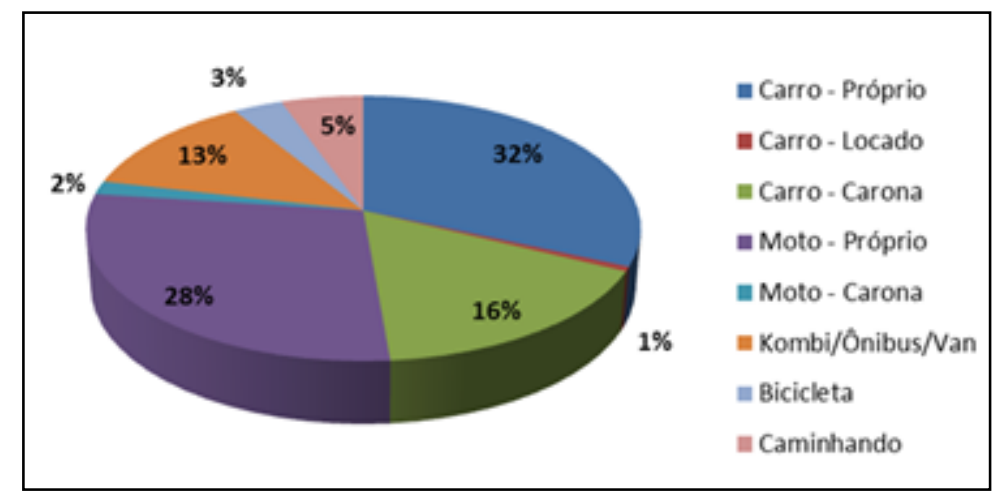

Fonte: Dados coletados pelos autores mediante questionário eletrônico.

Neste aspecto convém destacar a correlação com o fator relacionamento, pois alguns alunos relataram que tinham muita dificuldade de deslocar até o polo no início do curso, e à medida que as etapas eram concluídas, as amizades se consolidavam e o auxílio por meio de carona se efetivava. 


\section{FATORES MOTIVADORES PARA PERMANÊNCIA DOS DISCENTES DO CURSO DE

\subsection{DIMENSÃO COMPORTAMENTAL}

Esta dimensão abordou questões relacionadas com as razões mais influenciadoras para permanência dos alunos. Perguntou-se aos alunos se, em algum momento no curso, pensaram em abandonar. A pergunta foi aberta e as respostas foram agrupadas em ordem decrescente de rateio, conforme demonstrado na tabela 4 . Nota-se que aproximadamente $35 \%$ dos alunos não pensaram em desistir do curso. Porém, quase 65\% apresentaram uma razão pela qual poderiam ter desistido do curso. Essa dificuldade foi vencida e fez com que o aluno se sentisse incluído no contexto educacional.

Tabela 4 Resposta dos alunos quanto ao pensamento em desistir do curso, agrupadas por categoria. Dados reagrupados em ordem decrescente.

\begin{tabular}{lc}
\hline \multicolumn{1}{c}{ Resposta Agrupada } & Rateio \\
\hline Não & $34,97 \%$ \\
Sim - dificuldade na aprendizagem (tecnológica, forma ou conteúdo) & $23,50 \%$ \\
Sim - problemas familiares ou pessoais & $9,84 \%$ \\
Sim - falta de tempo ou organização para dedicação ao curso & $7,65 \%$ \\
Sim - falta de material de apoio para os estudos & $6,56 \%$ \\
Sim - mas sem uma razão específica & $6,56 \%$ \\
Sim - dificuldade de acesso ao polo & $5,46 \%$ \\
Sim - problemas financeiros & $3,28 \%$ \\
Sim - falta de feedback ou contato com os agentes educadores & $2,19 \%$ \\
\hline
\end{tabular}

Fonte: Dados coletados pelos autores mediante questionário eletrônico.

Este resultado pode ser confrontado com a pergunta, que indagava os alunos, quanto a percepção deles sobre a falta da base de estudos do ensino médio para acompanhar as disciplinas. O resultado está demonstrado no gráfico 4.

Gráfico 4 Relato quanto à dificuldade da base de estudos do ensino médio.

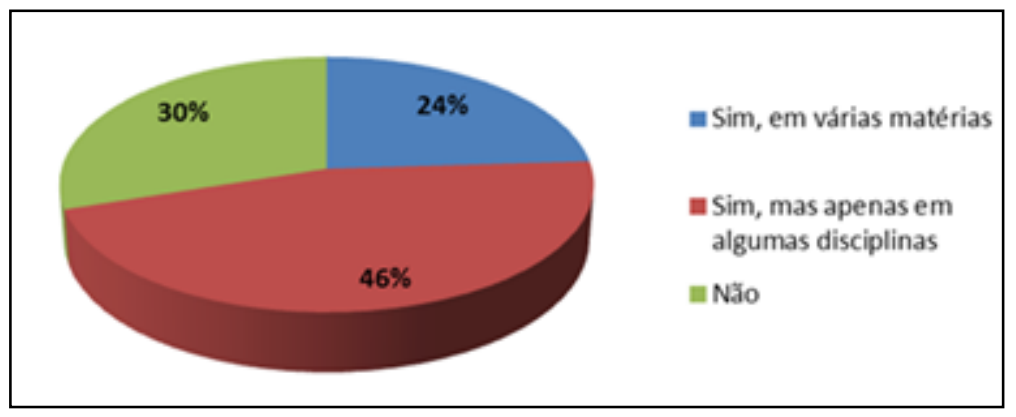

Fonte: Dados coletados pelos autores mediante questionário eletrônico. 


\section{FATORES MOTIVADORES PARA PERMANÊNCIA DOS DISCENTES DO CURSO DE

A dificuldade de aprendizagem (tecnológica, forma ou conteúdo) está relacionada com os alunos que sentiram falta da base de estudos do ensino médio. Outro fator que colabora pra isso é a faixa etária dos alunos, pois a maioria concluiu o ensino médio: há pelo menos, 10 anos.

Em seguida, os alunos foram questionados sobre quais os fatores motivadores que influenciavam a frequentar o curso. De acordo com a tabela 5, nota-se, por ordem decrescente, a obtenção de diploma de nível superior, interesse pela área de administração pública e carreira profissional, aperfeiçoamento dos conhecimentos e melhoria da situação financeira. Estes quatro fatores condizem com que afirmam os autores Knowles, Horton e Swanson (2011), a teoria da expectativa de Vroom (1995) e Cislaghi (2008), citados anteriormente.

Tabela 5 Resposta dos alunos quanto os fatores motivadores para frequentar o curso. Dados reagrupados em ordem decrescente.

\begin{tabular}{lc}
\hline \multicolumn{1}{c}{ Resposta Agrupada } & Rateio \\
\hline Obtenção de um Diploma de Nível Superior & $22,95 \%$ \\
Interesse pela área da Administração Pública e Carreira Profissional & $21,86 \%$ \\
Aperfeiçoar os conhecimentos & $19,13 \%$ \\
Melhora na situação financeira & $13,66 \%$ \\
Apoio da família & $4,92 \%$ \\
Estudar em uma IES pública renomada & $4,37 \%$ \\
Metodologia do curso & $3,83 \%$ \\
Nenhum fator motivador & $3,28 \%$ \\
Agentes envolvidos (professores, tutores e coordenações) & $3,28 \%$ \\
Ocupar o tempo & $1,64 \%$ \\
Acessibilidade ao polo & $1,09 \%$ \\
\hline
\end{tabular}

Fonte: Dados coletados pelos autores mediante questionário eletrônico.

Notou-se ainda uma preocupação com o futuro e um sentimento de amadurecimento e responsabilidade. Os alunos têm consciência que estão fazendo um investimento para o futuro e que a dedicação no curso é fundamental para garantir um futuro próspero e que atendam suas expectativas.

$\mathrm{Na}$ tabela 6 foram alocadas as respostas quanto aos fatores desmotivadores para os alunos frequentarem o curso. 


\section{FATORES MOTIVADORES PARA PERMANÊNCIA DOS DISCENTES DO CURSO DE \\ DOI: http://dx.doi.org/10.5007/1983-4535.2018v11n2p156}

Tabela 6 Resposta dos alunos quanto os fatores desmotivadores para frequentar o curso. Dados reagrupados em ordem decrescente.

\begin{tabular}{lc}
\hline \multicolumn{1}{c}{ Resposta Agrupada } & Rateio \\
\hline Nenhum fator desmotivador & $21,31 \%$ \\
Acesso e locomoção até o polo & $20,22 \%$ \\
Demora ou ausência de feedback de professores e/ou tutores EaD & $12,57 \%$ \\
Poucas atividades presenciais & $8,74 \%$ \\
Falta de tempo para dedicar aos estudos & $8,20 \%$ \\
Estudar sozinho & $4,92 \%$ \\
Problemas pessoais & $4,37 \%$ \\
Dificuldade com o uso da tecnologia & $3,28 \%$ \\
Falta de livros e materiais impressos & $2,73 \%$ \\
Falta de base de estudo do ensino médio & $2,73 \%$ \\
Alto nível das provas e atividades & $2,73 \%$ \\
Dificuldade na orientação de TCC & $2,19 \%$ \\
Dificuldade com a inconstância da internet & $2,19 \%$ \\
Problema de relacionamento entre colegas e/ou tutores presenciais & $2,19 \%$ \\
Desinteresse para atuar na área da formação & $1,64 \%$ \\
\hline
\end{tabular}

Fonte: Dados coletados pelos autores mediante questionário eletrônico.

\subsection{DIMENSÃO TECNOLÓGICA}

A dimensão tecnológica abrange os fatores ligados ao uso da informática e suas tecnologias. A tecnologia pode, em alguns casos, desmotivar o aluno a continuar o curso. $\mathrm{Na}$ tabela 6 apenas 3,28\% dos alunos apontaram alguma dificuldade com o uso das tecnologias. Pelo fato de estarem concluindo o curso, possivelmente já sanaram essa dificuldade. Se essa pesquisa for repetida no primeiro semestre (para os ingressantes), provavelmente esta dificuldade será mais acentuada. Apresenta-se a seguir os resultados compilados da dimensão tecnológica.

Inicialmente foi perguntado aos alunos se tinham dificuldades em usar o computador. Aproximadamente, $61 \%$ disseram não ter nenhuma dificuldade, $15 \%$ informaram ter dificuldade no início do curso, mas agora está superado, 20\% disseram ter pouca experiência no uso do computador e que possuem dificuldades e $4 \%$ alegaram ter dificuldades relacionadas ao AVA.

Questionados, se sentiam defasados tecnologicamente, 32,23\% disseram que sim e $67,77 \%$ disseram que não. Perguntados, se o polo propicia acesso aos computadores e a internet, $34,78 \%$ disseram que sim e que fazem uso, $28,70 \%$ disseram que sim, mas não fazem uso deles, $21,74 \%$ alegaram não saber, pois não fazem uso deles e 14,78\% responderam que não ou as vezes, pois nem sempre funcionam. Por fim, perguntou-se aos 


\section{FATORES MOTIVADORES PARA PERMANÊNCIA DOS DISCENTES DO CURSO DE

alunos se eles acreditavam que as ferramentas tecnológicas facilitam a comunicação e aprendizagem. Quase por unanimidade disseram que sim, representando 98,21\%.

\section{CONSIDERAÇÕES FINAIS}

Diante da análise realizada, é possível fazer algumas inferências e esboçar alternativas. A educação à distância exige métodos e metodologias de ensino desenvolvidos para atender as especificidades. Estabelecer um único modelo de ensino para atender públicos diferenciados é complexo e restringe o aprendizado. Em vez de pensar em uma única e melhor maneira de ensinar, deve-se pensar nas várias formas de ensinar, garantindo o atendimento das especificidades de cada local. Para tanto, o PNAP deveria possibilitar adequações a cada gestão de curso, mediante a realidade cultural, geográfica e socioeconômica.

A pouca possibilidade de interação entre aluno e professor em aula também dificulta o aprendizado. Isto poderia ser suprido se houvesse apenas um tutor (o presencial) e este fosse formado na área e atendesse as dúvidas dos alunos diretamente, intermediando o canal com o professor. Existe certa dificuldade de encontrar nos polos onde funcionam os cursos estudados esse profissional formado na área e que atenda os requisitos de contratação exigidos pela CAPES, porém com a colação de grau da primeira turma, esse obstáculo deve ser vencido. Além disso, deveria haver uma melhora na tecnologia usada nas aulas ao vivo, pois a que está em uso é precária e de baixa qualidade.

$\mathrm{O}$ EaD exige elevada capacidade de autonomia e determinação acadêmica de estudos pelo aluno. O apoio da família é fundamental para a continuidade dos estudos. Estudar consome as energias e a família exerce o papel de "carregador das baterias", metaforicamente expressando. Além da família, os colegas de sala e tutores presenciais também podem auxiliar ou suprir a carência afetiva de alguns alunos. As relações sociais são fundamentais para a constituição do sujeito.

Dentre os fatores que mais motivam os alunos a permanecerem no curso, constatou-se o apoio da família e dos agentes envolvidos, a expectativa da melhoria das condições financeiras após a conclusão do curso, a obtenção de um diploma de nível superior e o reconhecimento das pessoas próximas pelo esforço dedicado, que reconhecem o aluno concluinte como um vencedor, apto a integrar uma classe mais elevada da sociedade. $\mathrm{O}$ 
prestígio de estudar em uma IES pública e reconhecida nacionalmente e a área de atuação também foram fatores decisivos para permanência dos alunos.

A permanência requer ainda, competência docente elevada e que saiba diferenciar o ensino presencial do ensino EaD. Por meio de capacitações, os docentes são treinados a lidar com as especificidades desta metodologia de ensino. Porém muitos não conseguem se adaptar e acabam, por segurança, voltando ao método de ensino presencial. Além isso, notou-se também relatos de alunos que percebem a dificuldade do professor em lidar com a tecnologia ou que desacreditam ou fazem pouco caso dessa forma de ensino. Ministram aula pelo provimento da bolsa de fomento e não porque acreditam no EaD. A diversidade de mecanismos de comunicação dos tutores com os alunos favorecem o aprendizado e diminuem a dependência do professor. Os alunos utilizam além do AVA, redes sociais e estas auxiliam na troca de experiências e conhecimento. Os materiais didáticos elaborados pelo PNAP, bem como disponibilidade de tecnologias avançadas favorecem a aprendizagem. Porém, a falta de disponibilidade desses materiais impressos foi relatado como problema de aprendizado pelos alunos.

Outro ponto a se considerar é quanto ao acesso ao polo. Diversos alunos relataram problemas de acesso e mobilidade ao polo. Estradas esburacadas, pontes caídas, vias interditadas por excesso de chuvas e falta de transporte coletivo foram os problemas mais comuns. A resolução desses problemas cabe aos gestores governamentais. Recomenda-se, por fim, a implantação de uma avaliação institucional para o curso, para que os alunos também avaliem a estrutura de ensino e a gestão e possam fazer sugestões para a tomada de decisão e para as capacitações de docentes e tutores.

\section{REFERÊNCIAS}

ARISTOTÉLES. Política. 3. ed. Brasília: UnB, 1997.

BARDIN, Laurence. Análise de conteúdo. São Paulo: Edições 70, 2011.

BOLZAN, R. F. F. de A. O conhecimento tecnológico e o paradigma educacional. Dissertação (Mestrado em Engenharia de Produção) - Universidade Federal de Santa Catarina. Florianópolis, 1998.

CISLAGHI, Renato. Um modelo de sistema de gestão do conhecimento em um framework para a promoção da permanência discente no ensino de graduação. Tese (Doutorado em Engenharia e Sistema de Informação) - Universidade Federal de Santa Catarina. Florianópolis, 2008. 
DEWEY, John. Vida e educação. São Paulo: Melhoramentos, 1973.

KNOWLES, M. S; HOLTON, E. F.; SWANSON, R. A.The adult learner: the definitive classic in adult education and human resource development. 7. ed. Londres: Elsevier, 2011.

LARUCCIA, M. M.; ALMEIDA, R.; RUIZ, T. T. O Desenvolvimento das habilidades e competências profissionais de um grupo de estudantes de administração. Revista Científica Internacional: Inter Science Place, v. 3, n. 11, p. 142-165, jan./fev., 2010.

PEIXOTO, Maria do Carmo de Lacerda; BRAGA, Mauro Mendes. A evasão no ciclo básico da UFMG. In: ANPED, 21., 1998, Caxambú.. Disponível em http://www.anped11.uerj.br/21/PEIXOTO.htm . Acesso em 21 abr. 2015.

SARTORI, A. S. Educação a distância: novas práticas pedagógicas e as tecnologias da informação e comunicação. Linhas, v. 3, n. 2, p. 123-130, 2002.

SILVA FILHO, R. L. L. et al. A Evasão no Ensino Superior Brasileiro. Cadernos de Pesquisa, v. 37, n. 132, p. 641-659, 2007. Disponível em: http://goo.gl/qHsfr5 . Acesso em: $13 / 02 / 2015$.

VROOM, V. Work and Motivation, Jossey-Bass, San Francisco, CA, 1995.

VYGOTSKY, L. S. Pensamento e linguagem. São Paulo: Martins Fontes, 1993. 